Produto \& Produção, vol. 16 n.4, p. 32-47, dez. 2015

RECEBIDO EM 05/06/2015. ACEITO EM 30/09/2015.

\title{
Aplicação da teoria do portfólio na avaliação de uma empresa com três unidades de negócio.
}

\author{
Bruno Pereira Panissi \\ Universidade Federal de São Carlos - UFSCAR \\ bruno_panissi@hotmail.com
}

Jorge Luís Faria Meirelles

Universidade Federal de São Carlos - UFSCAR

jorgeluis@ufscar.br

\section{RESUMO}

Muitas empresas atuam no mercado por meio de diferentes unidades de negócio, ou seja, com segmentos distintos de produtos. Assim, torna-se importante verificar como cada unidade de negócio comporta-se frente às demais unidades e quais agregam mais valor à empresa como um todo. Este trabalho visa analisar o risco e retorno de cada unidade e seu efeito para a rentabilidade de uma empresa de bens de capital, que atua com três unidades de negócio, utilizando a teoria do portfólio proposta por Markowitz. Verificou-se que a unidade de máquinas-ferramenta, isoladamente, é a que apresenta a melhor relação risco-retorno. No contexto de formação de carteiras, foi possível verificar qual a proporção de investimento que deveria ser alocada em cada unidade de negócio de forma a obter a melhor relação risco e retorno.

Palavras-chave: risco-retorno, teoria do portfólio, Markowitz.

\begin{abstract}
Many companies operate in the market with different business units, which are distinct product segments. Thus, it becomes important to analyze how each unit behaves related to the others and which unit adds more value to the company. This study aims to analyze the risk and return of each unit and its effect on the risk and return of a goods company that operates in three sectors, using the theory of the portfolio proposed by Markowitz. It was concluded that the unit of machine-tools presents, singly, the best risk-return. Related to the context of forming portfolios, it was possible to verify the proportion of investment allocated to each business unit in order to obtain the best risk-return ratio.
\end{abstract}

Keywords: risk-return, theory of the portfolio, Markowitz 


\section{Introdução}

De acordo com Assaf Neto (2006), a preocupação em conhecer e entender o sistema financeiro e utilizar técnicas que ajudem na resolução de problemas enfrentados neste setor, bem como auxiliem na busca de uma maior rentabilidade para os negócios, é crescente ao longo do tempo devido a sua importância na economia e seu reflexo nas empresas. Tais problemas são preeminentes de cada época, obrigando o administrador a compreender o sistema financeiro como um todo a fim de proteger sua empresa dos concorrentes e/ou da falência e proporcionar o crescimento da companhia com o uso de ferramentas capazes de garantir decisões efetivas.

O impacto de crises em negócios, em regiões diferentes, foi verificado nas crises da Bolsa de Valores de Nova York (1929), 2a Guerra Mundial (1939-1945), desvalorização do Real (1999) e na recente desordem do subprime americano (2008), tendo efeito em economias do mundo todo. Somando-se a esses episódios, os avanços na tecnologia de informação permitiram uma nova sistemática nos mercados financeiros, admitindo o livre fluxo de capitais entre países para aqueles que desejam diversificar seus investimentos, porém, sofrendo com maior intensidade e rapidez com as oscilações econômicas (GUIMARÃES JUNIOR et al, 2011)

Desse modo, com a globalização e maior dependência entre países e empresas, investidores aplicam seus capitais em outras regiões ou negócios com a finalidade de obter vantagens e crescimento com suas aplicações, mas tornam-se mais vulneráveis aos riscos. Para "bloquear" tais riscos, administradores avaliam demonstrações contábeis e calculam índices que proporcionam informações relevantes e auxiliam em suas tomadas de decisão, visando maior retorno de suas aplicações ou minimização de seus riscos.

As avaliações financeiras permitem a diversificação dos investimentos com maior acurácia, seja no mercado financeiro, seja no mercado empresarial. Atentando-se para o segmento industrial, organizações utilizam essas análises para obter vantagem competitiva por meio do fornecimento de produtos diferentes aos consumidores, adotando uma estratégia de diversificação e apostando em negócios inéditos para novos mercados (ANDRADE, 2002).

As razões para que empresas adotem tal estratégia são lucrar nas suas aptidões centrais (utilizar suas fontes de vantagem competitiva em outros negócios), partilhar custos com a extensão de suas operações e, principalmente, reduzir os riscos, ou seja, diminuir a variabilidade dos retornos por meio da atuação em segmentos distintos (GOMES e MARREIROS, 2008).

Entretanto, esta metodologia de diversificação acarreta a necessidade de se investir em longo prazo, o que representa, para o administrador, o sacrifício de um retorno atual para a incerteza de um retorno futuro, pois não é possível prever com exatidão os benefícios futuros trazidos pelo investimento de hoje (SILVEIRA et al, 2006).

Portanto, muitas empresas atuam no mercado com segmentos distintos de produtos, os quais compõem diferentes unidades de negócio, buscando a redução de riscos. As vantagens e desvantagens da diversificação e a minimização dos riscos dependem de como tal estratégia é posta em prática pela organização. Assim, os administradores precisam de um método que forneça uma visão global de seus empreendimentos para decidirem, com maior clareza, como será a alocação de seus recursos nas diversas unidades que possuem.

Para auxiliar essas decisões de investimento, a Teoria do Portfólio de Markowitz (1952) relaciona os conceitos de risco e retorno para avaliar e otimizar o comportamento de uma carteira de investimentos dentro dos princípios de diversificação. Além disso, essa teoria pode ser uma ferramenta fundamental na avaliação do desempenho das unidades de negócio e de seus impactos na empresa como um todo.

Uma das primeiras tentativas de aplicação da teoria de portfólio em ativos não financeiros (ativos reais) foi feita por Cord (1964). Além disso, outros trabalhos também buscaram analisar unidades de negócio, tais como os trabalhos de Quick e Buck (1984), Jones (1985), Nepomuceno (1997), Howell III, Anderson e Bentz (1998), Brashear, Becker e Gabriel (1999), Orman e Duggan (1999), Walls (2004) e Simplício, Lemme e Leal (2012), em empresas do setor de petróleo; Roques, Newbery e Nuttall (2008), Delarue et al (2011) e Allan et al (2011), no setor de energia elétrica; Roques, Hiroux e Saguan (2010) e Medimorec e Tomsic (2015), em investimentos em energia eólica; Guerrero-Lemus, Marrero e Puch (2012), na análise de combinação de fontes de combustível no setor de transporte rodoviário; Andrade e Famá (1999), no setor de telecomunicações; Gao et al (2014), na 
análise da matriz energética chinesa; Akter, Kompas e Ward (2015), na alocação de recursos para controle biológico de espécies invasivas; e Byers et al (2015), na otimização do uso de recursos (humanos, financeiros, serviços, etc.) em sistemas de produção.

Portanto, o presente trabalho tem por objetivo analisar o comportamento de cada unidade de negócio frente às demais e seu efeito no risco e retorno de uma empresa de bens de capital, verificando qual unidade atribui maior valor para a empresa e o que pode ser feito para elevar o retorno da companhia. Tal empresa é composta por três unidades de negócio e, por meio da Teoria do Portfólio e das informações contábeis trimestrais referentes ao período de 2006 a 2013, buscou-se verificar a melhor relação risco e retorno dos segmentos.

\section{Referencial teórico}

Historicamente, o entendimento e preocupação com os riscos a serem enfrentados surgiram no Renascimento, época em que as pessoas começaram a afrontar, de maneira explícita, as consagradas crenças e assumiram as consequências por tais atitudes (BERNSTEIN, 1997).

Ainda nesse contexto de acontecimentos históricos, em meados do Século XX, após a crise da Bolsa de Valores de Nova York e a $2^{\mathrm{a}}$ Guerra Mundial perturbarem a estabilidade de diversas economias e ascenderem à necessidade de reestruturação de inúmeros países, empresas do mundo todo vislumbraram a oportunidade de intervir em diversos segmentos e oferecer ao mercado vários produtos distintos que atendessem mais de um tipo de cliente.

Ainda no Século XX, a economia mundial enfrentou as crises do petróleo (1973 e 1979) com um aumento substancial nas cotações do barril de petróleo. O processo da globalização aproximou os países e elevou as suas trocas comerciais (produtos e serviços) e os avanços na tecnologia de informação facilitaram o livre fluxo de capitais entre as nações. Assim, a intensificação dessas trocas gerou uma dependência maior entre os países e sugere que uma crise econômica de um único país resulte na contaminação dos demais (FAMÁ, SAITO e SAVOIA, 2006). Para Famá e Galdão (1996) essa relação entre os mercados leva a uma maior preocupação com a gestão de riscos.

A consequência da globalização e do aumento das relações comerciais entre os países acarreta uma maior concorrência entre as empresas do mundo todo e, portanto, um maior esforço pela sobrevivência neste cenário de intensa disputa. Conforme Damodaran (2004), para enfrentar essas condições, qualquer decisão que eleva o valor da empresa é considerada uma estratégia promissora, sendo que, restringindo um pouco mais esse conceito de valor de empresa, o mesmo é alcançado com o aumento do preço das ações, o qual pode ser conseguido por meio da diversificação, exemplificada pela Matriz de Ansoff (Figura 1).

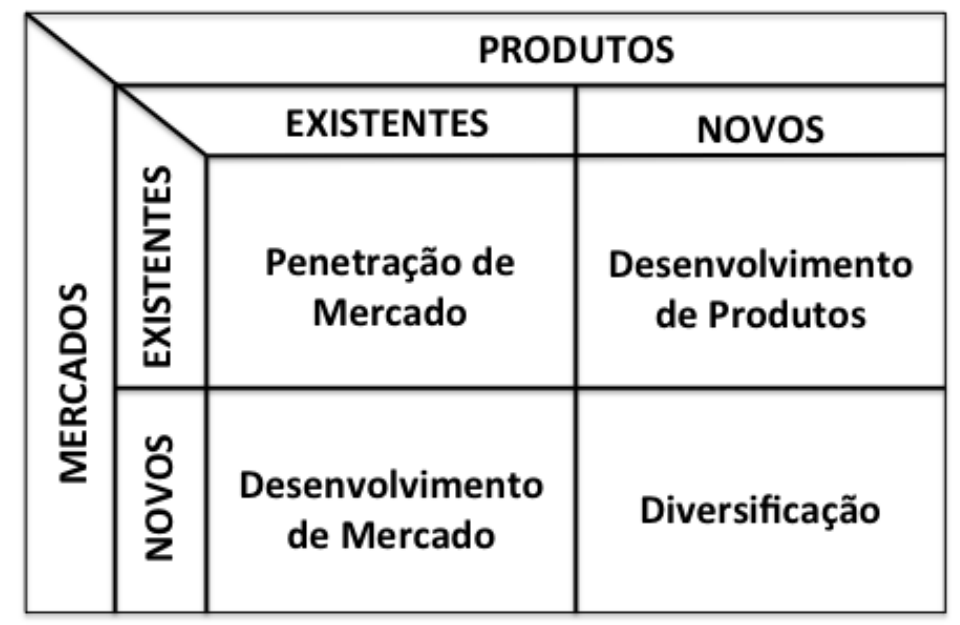

Figura 1 - Matriz de Ansoff

Fonte: Gomes e Marreiros (2008)

Desenvolvida por Igor Ansoff, conhecido como o pai da gestão estratégica, a matriz de Ansoff é utilizada para definir oportunidades de crescimento de unidades de negócio de uma organização 
(GOMES e MARREIROS, 2008). Ao investir em um novo mercado com novos produtos, a empresa adota um processo de diversificação visando superar seus concorrentes, manter-se no mercado e maximizar o valor de suas ações.

Entretanto, Andrade (2002) salienta que argumentos teóricos indicam que a diversificação pode tanto aumentar o valor da empresa quanto diminuí-lo, devendo o empresário analisar a influência dessa estratégia no desempenho da organização.

Atentando-se para o setor financeiro, a diversificação ocorre por meio de aplicações em investimentos distintos e depende do perfil do investidor, especialmente no grau de risco ao qual está disposto a assumir. Essas decisões não são tomadas em um cenário de total garantia com relação aos futuros resultados, devendo ser realizada uma crítica análise do risco e retorno das aplicações.

Uma maneira de se definir o risco é a incerteza dos resultados futuros ou a probabilidade de eventos de insucesso, bem como de um efeito adverso (BROWN e REILLY, 2010). Exemplos de risco são alterações na economia e tecnologia, crescimento da concorrência e dos preços dos insumos, endividamento, entre outros. Já o retorno refere-se à esperança positiva que os possíveis valores podem assumir, como um aumento de vendas ou alta no preço das ações. Foi utilizando-se desses conceitos (risco e retorno) que na década de 50 foi elaborada a Moderna Teoria do Portfólio.

Os estudos financeiros permaneceram estagnados até essa década, sendo as teorias, até então normativas e inconsistentes, utilizadas apenas nas melhores práticas de financiamentos e investimentos. Após essa época, as abordagens buscaram entender e analisar as consequências dessas práticas no desempenho do fluxo de caixa, níveis de risco e valor da empresa (SMITH, 1984).

Assim, em 1952, Harry Markowitz iniciou a formulação e desenvolvimento do estudo do portfólio e da teoria de diversificação de investimentos. Ele apresentou, no The Journal of Finance, o artigo Portfolio Selection, o qual comprovou que, para obter ganhos, um investidor deve compor uma carteira com base em seu retorno desejado e na variância desses retornos (riscos), de modo a aumentar o primeiro e minimizar o segundo por meio da diversificação de investimentos que possuem baixo ou nenhum nível de covariância (FAMÁ, SAITO e SAVOIA, 2006). Como levantado por Bernstein (1997), a moderna teoria das carteiras contrariou o senso comum da época, que visava a alocação dos recursos no ativo de maior retorno esperado, ao apresentar a diversificação como formadora de melhores carteiras.

Vale ressaltar que, quaisquer que sejam os meios utilizados para formar carteiras, não existe um método genérico de diversificação que satisfaça as expectativas de cada investidor, assim como é uma decisão difícil a maneira de alocação dos recursos entre os vários investimentos. O horizonte de tempo, a tolerância ao risco e a experiência pessoal são fatores importantes na melhor composição dos investimentos (BODIE, KANE e MARCUS, 2010).

Conforme Brown e Reilly (2010) e Bodie, Kane e Marcus (2010), a taxa de retorno que se espera de uma carteira é a média ponderada das taxas esperadas de retorno de cada ativo que a compõe e o peso de cada ativo é a proporção do valor total do investimento alocado nele (Equação 1).

$$
R e=\sum_{i=0}^{n} w_{i} x_{i}
$$

em que:

$R e=$ retorno da carteira

$w_{i}=$ proporção do capital investido no ativo $i$

$x_{i}=$ retorno proporcionado pelo ativo $i$

No caso de uma empresa que investe em diferentes unidades de negócio, o $w_{i}$ seria a proporção do capital total que foi investida na unidade $i$ e $x_{i}$ seria o retorno proporcionado pela mesma, medido pelo retorno sobre o investimento (ROI - return on investment).

Ainda no contexto das empresas, Alberton (2003) e Lima e Silva (2009) citam que o ROI é um dos indicadores mais utilizados, pois evidencia a rentabilidade da organização. Além disso, as empresas diversificam-se ao investir em unidades que atuam em segmentos distintos, sendo o ROI de cada uma delas utilizado no cálculo do retorno da empresa como um todo. Caso a empresa resolva iniciar uma nova unidade, o retorno dessa deve ser maior ou no mínimo igual ao retorno da empresa para que não ocorra um valor presente negativo (ANDRADE e FAMÁ, 2001). 
O retorno sobre o investimento (Equação 2) demonstra a capitalização proporcionada pelo lucro operacional (líquido do imposto de renda) em relação ao investimento (composto pelo patrimônio líquido mais o passivo oneroso da empresa). Espera-se uma rentabilidade que seja capaz de remunerar o passivo oneroso, com base no custo financeiro, e o patrimônio líquido, por meio da distribuição de lucros, além de gerar riqueza, revelando a eficiência econômica da empresa (DAMODARAN, 2007).

$$
R O I=\frac{\text { Lucro operacional }(\text { Liq.IR })}{\text { Investimento }}
$$

Conforme Assaf Neto (2006), o passivo oneroso (dívidas) corresponde aos financiamentos e empréstimos adquiridos no mercado financeiro, expressando o custo efetivo das contratações de créditos e contidos no passivo circulante e no não circulante das demonstrações contábeis das empresas. O patrimônio líquido refere-se ao capital próprio da empresa, correspondente às suas ações, acrescido de seus ganhos.

Atrelado ao conceito de retorno, o risco é a parcela imprevista do retorno, resultante de eventos inesperados ou de insucesso, representando possibilidades de prejuízos financeiros ou efeitos indesejáveis (BAMPI, CAMARGO e COLOMBO, 2009). Os retornos reais conseguidos com um investimento podem ser diferentes dos retornos esperados e é essa diferença que representa o risco, ou seja, o desvio dos retornos reais em relação aos retornos esperados (DAMODARAN, 2004). Assim, o cálculo do risco de cada unidade é apresentado pela Equação 3.

$$
\sigma_{i}=\sqrt{\frac{\sum_{t=1}^{n}\left(Y_{t}-\bar{Y}\right)^{2}}{n-1}}
$$

em que:

$\sigma_{i}=$ risco do ativo $i$ (calculado pelo desvio padrão de seus retornos)

$Y_{t}=$ retorno da observação $t$

$\overline{\mathrm{Y}}=$ média dos retornos

$\mathrm{n}=$ número de observações da amostra

Já o risco referente à carteira é mostrado pela Equação 4 e as decisões tomadas devem visar a redução desse risco.

$$
\sigma \rho=\left[\sum_{i=1}^{n} w_{i}^{2} \sigma_{i}^{2}+\sum_{i=1}^{n} \sum_{j=1}^{n} w_{i} w_{j} \rho_{i j} \sigma_{i} \sigma_{j}\right]^{1 / 2}
$$

em que:

$\sigma p=$ risco da carteira (calculado pelo desvio padrão dos retornos das unidades)

$w_{i}=$ participação da cada ativo no total da carteira

$\sigma_{\mathrm{i}}=$ desvio padrão do retorno do ativo $i$

$\rho_{i j}=$ correlação entre os ativos $i$ e $j$

O desvio padrão é uma medida estatística que indica a dispersão (grau de afastamento de valores em relação à média) dos valores dos retornos esperados, sendo que quanto maior essa dispersão, maior a incerteza dos resultados futuros e, portanto, maior o risco que se corre (BROWN e REILLY, 2010; CLARK e DOWNING, 2006).

Assaf Neto (2006) e Bodie, Kane e Marcus (2010) observam que o risco global de uma carteira é constituído por dois elementos: risco sistemático e risco não sistemático. O risco sistemático, ou risco de mercado, é aquele causado pelas condições econômicas a que está sujeito o sistema, sendo originado pelas flutuações nas taxas de juros, no comportamento das tarifas de títulos, nas inflações, dentre outros fatores, não podendo ser eliminado pelo processo de diversificação (risco não diversificável). Em contrapartida, o risco diversificável, ou risco não sistemático, é um risco específico da empresa e pode ser eliminado pela estratégia de diversificação. 
Considerando as duas parcelas (risco e retorno) que influenciam a eficiência de uma carteira, a seleção da mesma deve se basear em uma análise de como é possível investir de forma a compensar os riscos proporcionados com os retornos desejados e, assim, encontrar a melhor carteira de ativos. A finalidade da seleção de carteiras é combinar diversos ativos para obter uma carteira que resulte em um maior retorno para um determinado nível de risco ou que provoque um menor risco para certo nível de retorno exigido (DAMODARAN, 2004).

Portanto, para que uma carteira seja considerada eficiente, nenhuma outra carteira deve existir com menor risco para determinada taxa de retorno esperada ou, alternativamente, nenhuma outra carteira seja obtida com maior retorno para certa taxa de risco que se esteja disposto a correr (GONÇALVES, MORAES e PIMENTA, 2010). Essas possíveis carteiras ótimas são estimadas pela fronteira eficiente, que consiste em uma demonstração gráfica desse conjunto de portfólios com melhor relação risco-retorno (Figura 2). Tal fronteira eficiente evidencia as melhores escolhas de carteiras com diferentes combinações de investimentos, porém não especifica qual deve ser selecionada, devendo essa escolha ser baseada na experiência pessoal, horizonte de tempo, dentre outros fatores.

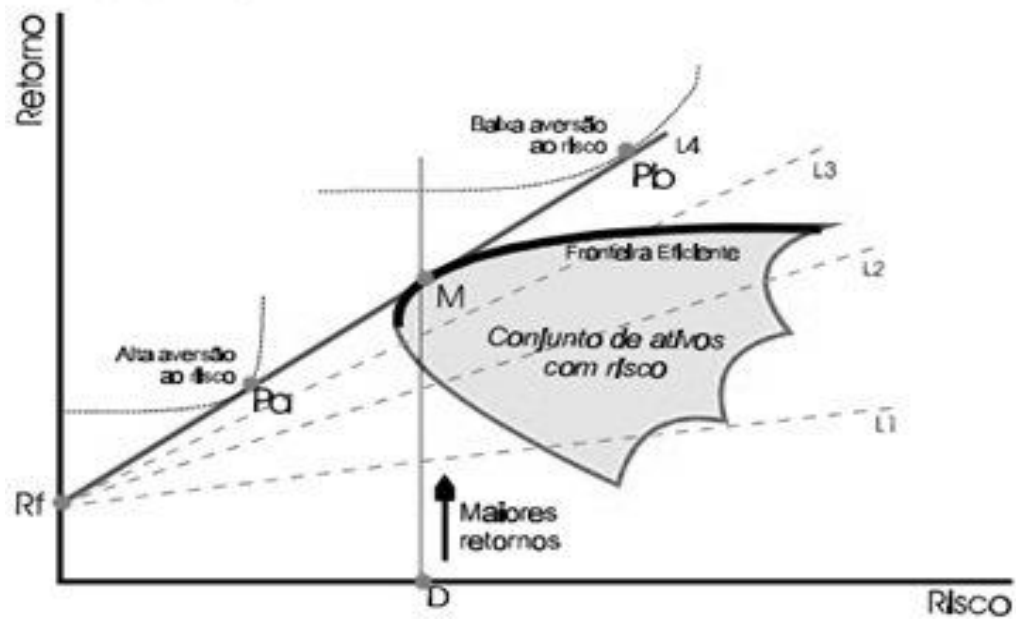

Figura 2 - Fronteira Eficiente

Fonte: Bruni e Famá (1998).

Markowitz (1959) complementa a análise da fronteira eficiente ao expor que não se deve preocupar com o risco do ativo individual, mas sim com a relação entre os ativos e a sua contribuição ao risco total da carteira. Assim, o cálculo do risco total abrange também a correlação entre os ativos (calculado por meio do coeficiente de correlação apresentado pela Equação 5), de modo que uma variação no valor de um ativo possa ser compensada por variações inversas nos outros, resultando em uma variação pequena na carteira.

$$
\rho=\frac{\sum_{i=1}^{n}\left(x_{i}-\bar{x}\right)\left(y_{i}-\bar{y}\right)}{\sqrt{\sum_{i=1}^{n}\left(x_{i}-\bar{x}\right)^{2}} \cdot \sqrt{\sum_{i=1}^{n}\left(y_{i}-\bar{y}\right)^{2}}}
$$

em que:

$\rho=$ coeficiente de correlação entre duas unidades

$x_{i}=$ retorno do ativo $x$ referente à observação $i$

$\bar{x}=$ média dos retornos do ativo $x$

$y_{i}=$ retorno do ativo $y$ referente à observação $i$

$\bar{y}=$ média dos retornos do ativo $y$

$\mathrm{n}=$ número de observações

Sendo assim, a base para que o processo de diversificação ocorra de forma a acarretar a melhor relação risco-retorno depende fundamentalmente da correlação entre os retornos dos ativos. $\mathrm{O}$ 
coeficiente de correlação reflete o grau de relacionamento entre dois fatores, sendo que seu valor encontra-se no intervalo de -1 a +1 . Caso os fatores sejam independentes, o valor obtido (correlação) será zero. O coeficiente será positivo se as variáveis relacionarem-se diretamente (de modo igual). Por outro lado, caso relacionem-se inversamente, a correlação será negativa (CLARK e DOWNING, 2006). A equação do coeficiente de correlação expressa tanto o sentido da correlação (positivo ou negativo), quanto a intensidade (mais ou menos próximo de 1), sendo que quanto mais próximo de 1 , maior a intensidade.

Essa constatação contraria as primeiras teorias sobre o tema, pois, antes dos estudos de Markowitz, associavam-se a relação risco-retorno a uma reta, como se agissem proporcionalmente. Após as análises da teoria de portfólio, notou-se que a combinação de ativos que possuem correlações positivas e altas não traria significativa minimização do risco, pois esses ativos são afetados de forma semelhante quando ocorrem oscilações econômicas (SECURATTO, 1997). Bodie, Kane e Marcus (2010) complementam a análise comentando que as melhores oportunidades de carteiras são aquelas que têm ativos não perfeitamente correlacionados, sendo que quanto mais próximo de -1 melhor.

Portanto, a teoria do portfólio de Markowitz propõe que as melhores carteiras são conseguidas por meio da diversificação de ativos, obtida com a análise dos retornos almejados e dos possíveis riscos corridos, relacionando ativos que possuem correlação próxima ou igual a -1 , ou seja, que apresentem reação de forma inversa às oscilações econômicas.

No entanto, a seleção de ativos reais pelas empresas não incorpora o procedimento de otimização de média-variância da mesma forma que ocorre na seleção de ativos financeiros para carteiras de investimento. Enquanto a ordenação dos projetos enfatiza a maximização do retorno, a teoria de carteiras enfatiza a relação risco-retorno. O método de otimização de carteiras pode ser um elemento adicional a ser considerado na decisão do orçamento de capital (SIMPLICIO, LEMME e LEAL, 2012).

Para Lemme (2001), os principais problemas relacionados à aplicação de modelos de precificação de ativos financeiros para a avaliação de ativos reais são: a indivisibilidade dos ativos; a dificuldade ou impossibilidade de repetição dos eventos, reduzindo a utilidade das medidas estatísticas de desempenho (baseadas na ocorrência de eventos sucessivos); a pouca liquidez; os custos de transação elevados; a assimetria de informação entre os investidores; a inexistência de um mercado formal que dê transparência às transações efetuadas; e a concentração dos investidores em determinados segmentos de negócios por conta de conhecimentos tecnológicos ou de gestão, dificultando a formação de carteiras diversificadas de ativos reais.

Nesse contexto, o presente trabalho analisou uma empresa como sendo uma carteira, formada por três unidades de negócio, com seus respectivos retornos, riscos e correlações, visando identificar como cada unidade contribui para a relação risco-retorno da empresa e qual seria a proporção de investimento ótima em cada uma, segundo a teoria do portfólio.

\section{Metodologia}

A presente pesquisa corresponde ao estudo de caso de uma empresa de bens de capital, a qual é uma sociedade anônima de capital aberto e, por isso, as informações financeiras necessárias para a realização dessa pesquisa são divulgadas publicamente. Logo, os dados e as informações financeiras pertinentes para o desenvolvimento desse trabalho foram obtidos por meio das demonstrações contábeis publicadas trimestralmente pela organização, além de informações divulgadas por meio de relatórios anuais.

Foram utilizadas as demonstrações contábeis desde o primeiro trimestre de 2006 (quando a empresa iniciou a divulgação de informações individuais sobre cada unidade), até o terceiro trimestre de 2013.

Os resultados encontrados de cada unidade foram confrontados entre si para aferir a influência de cada uma delas no risco e retorno da empresa (carteira) como um todo. 


\section{Descrição da empresa}

A "Indústrias Romi S.A.”, empresa foco deste trabalho, foi fundada em 1930 na cidade de Santa Bárbara d'Oeste, interior paulista (ROMI, 2012). Essa organização iniciou suas atividades a partir de uma pequena oficina de reparos e consertos de automóveis, com o nome de "Garage Santa Bárbara".

A pequena oficina expandiu suas atividades com a fabricação de máquinas agrícolas e tornos mecânicos, os quais representaram um grande avanço para a empresa devido às suas exportações, logo no início dos anos 40. Mais tarde, em 1962, com aumento do portfólio dos produtos oferecidos ao mercado, houve a alteração da razão social para "Indústrias Romi S.A.", tornando-se, posteriormente, uma Sociedade Anônima de capital aberto. Já em meados dos anos 80 criou-se, nos EUA, a Romi Machine Tools Ltda, uma subsidiária da organização para dar suporte à distribuição de seus produtos no mercado norte-americano (ROMI, 2012).

Hoje, as instalações fabris da empresa estão divididas em duas localidades: uma em Santa Bárbara d'Oeste, interior paulista, e outra em Grugliasco e Pont Canavese, região de Turim (Itália), realizando processos de usinagem, montagem final de máquinas industriais, fundidos, chaparia e montagem de painéis eletrônicos.

A empresa conta com três unidades de negócio, compreendendo as seguintes atuações: máquinas-ferramenta, máquinas (injetoras) para plásticos e fundidos e usinados (ROMI, 2012). Essas unidades de negócio são apresentadas a seguir.

\subsection{Máquinas-ferramenta}

As máquinas-ferramenta são destinadas à produção de peças de diversos materiais, tamanhos e formatos por meio da movimentação mecânica de um conjunto de aparelhos. Seu funcionamento consiste em girar a peça a ser usinada e que se encontra fixada em um cabeçote, enquanto algum instrumento de corte vai de encontro à superfície da peça removendo material de acordo com as especificações técnicas. Dentro dessa categoria, a Romi dedica-se a fabricar tornos, centro de torneamento e de usinagem, mandrilhadoras, etc. (ROMI, 2012).

Expandindo essa categoria, dentro do segmento torno a empresa fabrica, por exemplo, a Linha ROMI T, que são tornos universais para trabalhos de ferramentaria, produção e manutenção e que possuem inúmeras possibilidades de velocidade de corte e avanços (ROMI, 2012).

\subsection{Máquinas para plásticos}

Esta classe de equipamentos destina-se a fabricar peças constituídas de materiais plásticos por meio da inserção do material fundido dentro de um molde que dará a configuração desejada após a solidificação do plástico. Dentro dessa categoria encontram-se as injetoras e sopradoras (ROMI, 2012).

\subsection{Fundidos e usinados}

Este segmento é dotado de instalações, equipamentos e processos que permitem a produção de peças em ferro cinzento, nodular ou vermicular. Este conjunto de aparelhagem garante a obtenção e repetibilidade das características metalúrgicas das ligas produzidas (ROMI, 2012).

Além disso, possui uma estrutura de moldagem e macharia, que permite atender ampla variedade de clientes e mercados, bem como oferecer os fundidos já usinados com o intuito de diminuir o lead time e os custos de rejeitos e de logística (ROMI, 2012).

\section{Resultados}

A partir das demonstrações contábeis da empresa, foram coletados os dados necessários para os cálculos dos indicadores pertinentes ao objetivo deste trabalho. Tais indicadores envolvem o risco, 
o retorno e a matriz de correlação entre as unidades, de modo a proporcionar a análise da empresa por meio da teoria do portfolio.

Assim, para o cálculo do retorno sobre o investimento (ROI), índice necessário para a aplicação de teoria de Markowitz, foi preciso obter, primeiramente, o lucro operacional líquido do imposto de renda (IR) e o investimento destinado a cada unidade.

O lucro operacional é encontrado diretamente nas demonstrações contábeis da empresa, porém necessita-se descontar o IR. Para o caso da empresa analisada, foi considerada a alíquota de $34 \%$ de IR.

O outro componente para o cálculo do ROI é o investimento, que compreende o somatório do patrimônio líquido com o passivo oneroso, os quais são obtidos através dos balanços patrimoniais da empresa. O patrimônio líquido também é encontrado diretamente nos balanços divulgados pela empresa. Já para a obtenção dos dados do passivo oneroso, foram somados os valores referentes aos financiamentos, empréstimos e debêntures, tanto de curto quanto de longo prazo, pois são fatores que geram despesas financeiras.

Tanto o passivo oneroso quanto o patrimônio líquido não são divulgados para cada unidade de negócio, ao contrário do valor do imobilizado. Sendo assim, calculou-se a proporção do capital imobilizado referente a cada unidade, para cada trimestre.

Considerando a média do imobilizado no período, entre o primeiro trimestre de 2012 (1T/2012) e o terceiro trimestre de 2013 (3T/2013), a unidade de máquinas-ferramenta é a que possui a maior parte do imobilizado da empresa (cerca de 60\%), enquanto que fundidos e usinados representa cerca de $36 \%$ e máquinas para plásticos apresenta a menor participação (4\%).

Com base na proporção do imobilizado, tomando essa variável como uma proxy, foi calculada a proporção do investimento que caberia a cada unidade.

O Gráfico 1 apresenta o comportamento do ROI de cada unidade de negócio ao longo do período analisado.

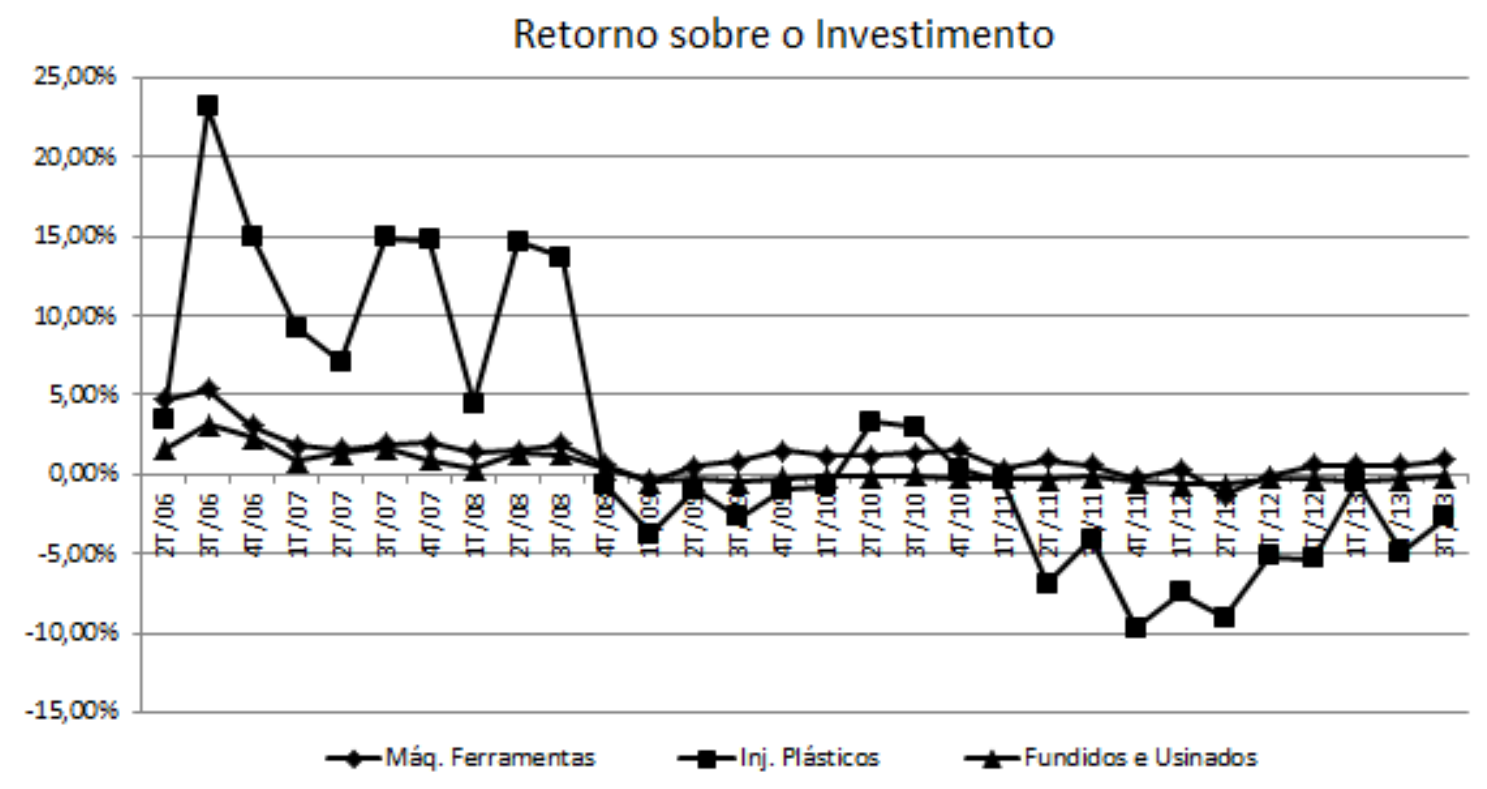

Gráfico 1 - Retorno sobre o Investimento (ROI) da cada unidade

Observa-se que a unidade máquinas (injetoras) para plásticos apresenta um ROI relativamente elevado, em média, entre 2006 e 2008 quando comparado com as demais unidades. No entanto, a rentabilidade dessa unidade teve uma queda brusca no quarto trimestre de 2008 , mantendo-se em níveis negativos após 2009 (com exceção para 2010, em que atinge patamares positivos, porém pouco expressivos, após o segundo trimestre). Analisando todo o período, essa unidade é a que possui o ROI com variações consideráveis, ao contrário das outras, que possuem o ROI praticamente estável. 
A unidade máquinas-ferramenta apresentou um ROI negativo no 1T/2009, mas voltou para patamares positivos no trimestre seguinte. Após 2009 apresentou um ROI negativo somente no final de 2011 e meados de 2012.

Já a unidade fundidos e usinados passou a apresentar ROI negativo no 1T/2009 e assim perdurou até o 3T/2013. Tal comportamento pode ser explicado pela crise financeira iniciada em 2008, que ocasionou a retração da economia e dificultou os investimentos em diversos seguimentos.

A partir da série trimestral do ROI, foram calculados o ROI médio (considerado como medida de retorno) e o desvio padrão (considerado como medida de risco) inerentes a cada unidade, como mostra o Gráfico 2.

A unidade que apresentou maior retorno foi máquinas (injetoras) para plásticos $(2,03 \%)$, mas também foi a que apresentou o maior risco $(8,45 \%)$, o que era de se esperar, pois, quanto maior o retorno, maior o risco que se corre. A unidade de máquinas-ferramenta apresentou um retorno de $1,24 \%$ e risco de $1,35 \%$, enquanto que fundidos e usinados apresentou um retorno de $0,30 \%$ para um risco de $0,97 \%$.

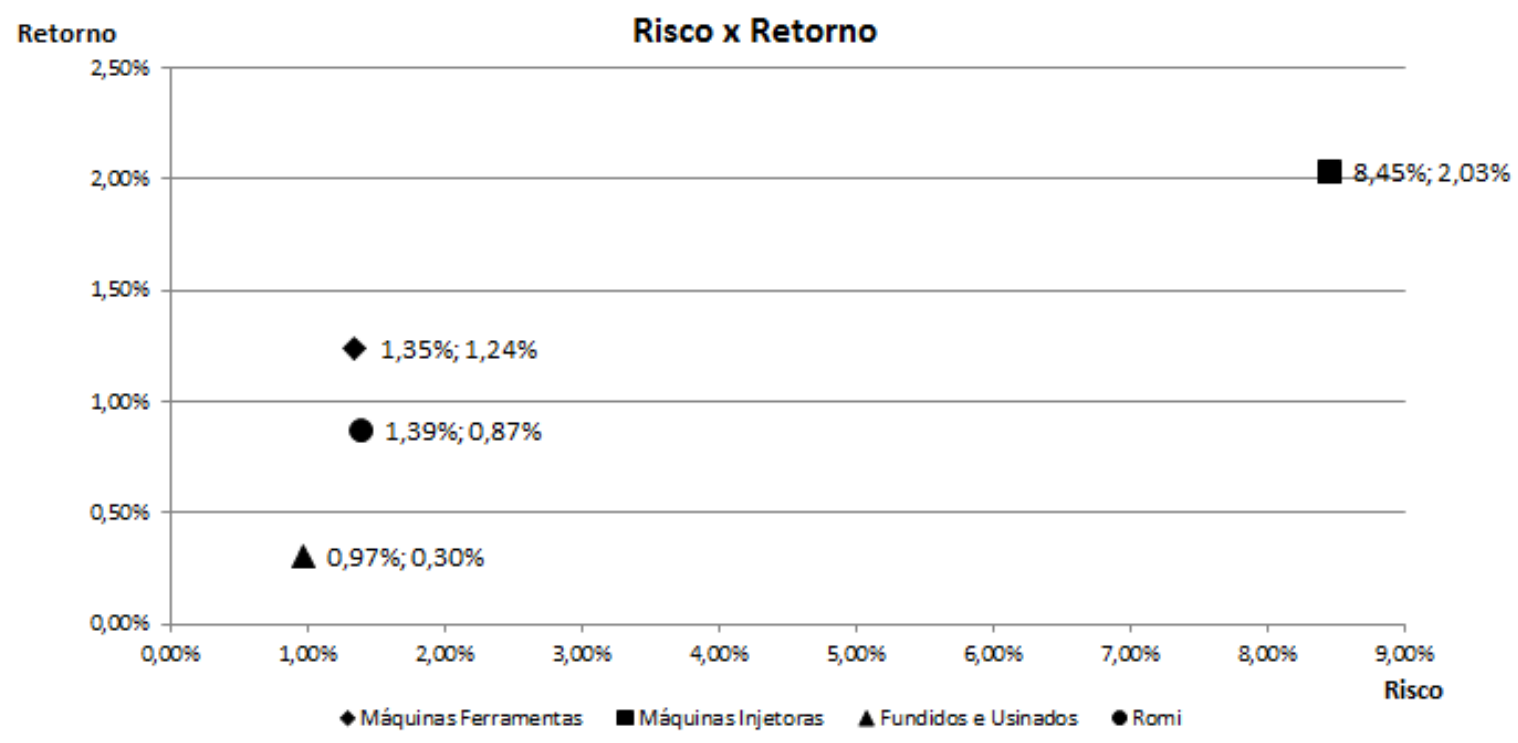

Gráfico 2 - Relação Risco-Retorno das unidades

Para que se tenha uma melhor compreensão dos dados e uma análise mais apurada, calculouse o Coeficiente de Variação (CV = Risco/Retorno) de cada unidade. Tal indicador mostra qual o risco incorrido para cada unidade de retorno. Assim, o CV é por volta de 1,09 para máquinas-ferramenta, enquanto que para fundidos e usinados é igual a 3,23 e para máquinas para plásticos é de 4,16, sendo esta última a unidade que apresenta o maior risco para cada unidade de retorno que proporciona. Analisando conjuntamente o Gráfico 2 e os resultados do coeficiente de variação, pode-se observar que a unidade máquinas para plásticos possui o maior retorno dentre todas elas, porém é a que apresenta o maior risco, não sendo satisfatório para investidores avessos ao risco. Por outro lado, a unidade fundidos e usinados apresenta o menor risco, mas seu retorno também é baixo e, quando analisado seu CV, há uma grande parcela de risco para cada unidade do retorno. Assim, a unidade que apresenta uma relação risco-retorno relativamente mais equilibrada é máquinas-ferramenta, pois mesmo não sendo a que possui o maior retorno ou menor risco, quando analisado em conjunto estes dois fatores, seu CV é baixo.

No entanto, para aplicar a teoria de carteiras, além da análise do risco e do retorno, é preciso verificar como as unidades correlacionam-se, conforme apresenta a Tabela 1. 
Tabela 1- Matriz de Correlação entre as unidades

\begin{tabular}{cccc}
\hline UN & $\begin{array}{c}\text { Máquinas } \\
\text { Ferramenta }\end{array}$ & $\begin{array}{c}\text { Máquinas para } \\
\text { Plástico }\end{array}$ & $\begin{array}{c}\text { Fundidos e } \\
\text { Usinados }\end{array}$ \\
\hline \hline $\begin{array}{c}\text { Máquinas } \\
\text { Ferramenta }\end{array}$ & 1 & 0,76 & 0,85 \\
\hline $\begin{array}{c}\text { Máquinas para } \\
\text { Plástico }\end{array}$ & 0,76 & 1 & 0,90 \\
\hline $\begin{array}{c}\text { Fundidos e } \\
\text { Usinados }\end{array}$ & 0,85 & 0,90 & 1 \\
\hline
\end{tabular}

É possível verificar que as três unidades são fortemente correlacionadas, pois estão inseridas no segmento de bens de capital, apresentando comportamento parecido quando expostas às mudanças que afetam o setor, o que diminui o efeito da diversificação do risco ao ponderar a distribuição de investimentos entre elas.

Com a determinação do retorno e do risco de cada unidade e da correlação entre as mesmas, foi possível gerar, por meio do solver da planilha eletrônica Excel, a fronteira eficiente, conforme apresentada no Gráfico 3.

\section{Fronteira Eficiente}

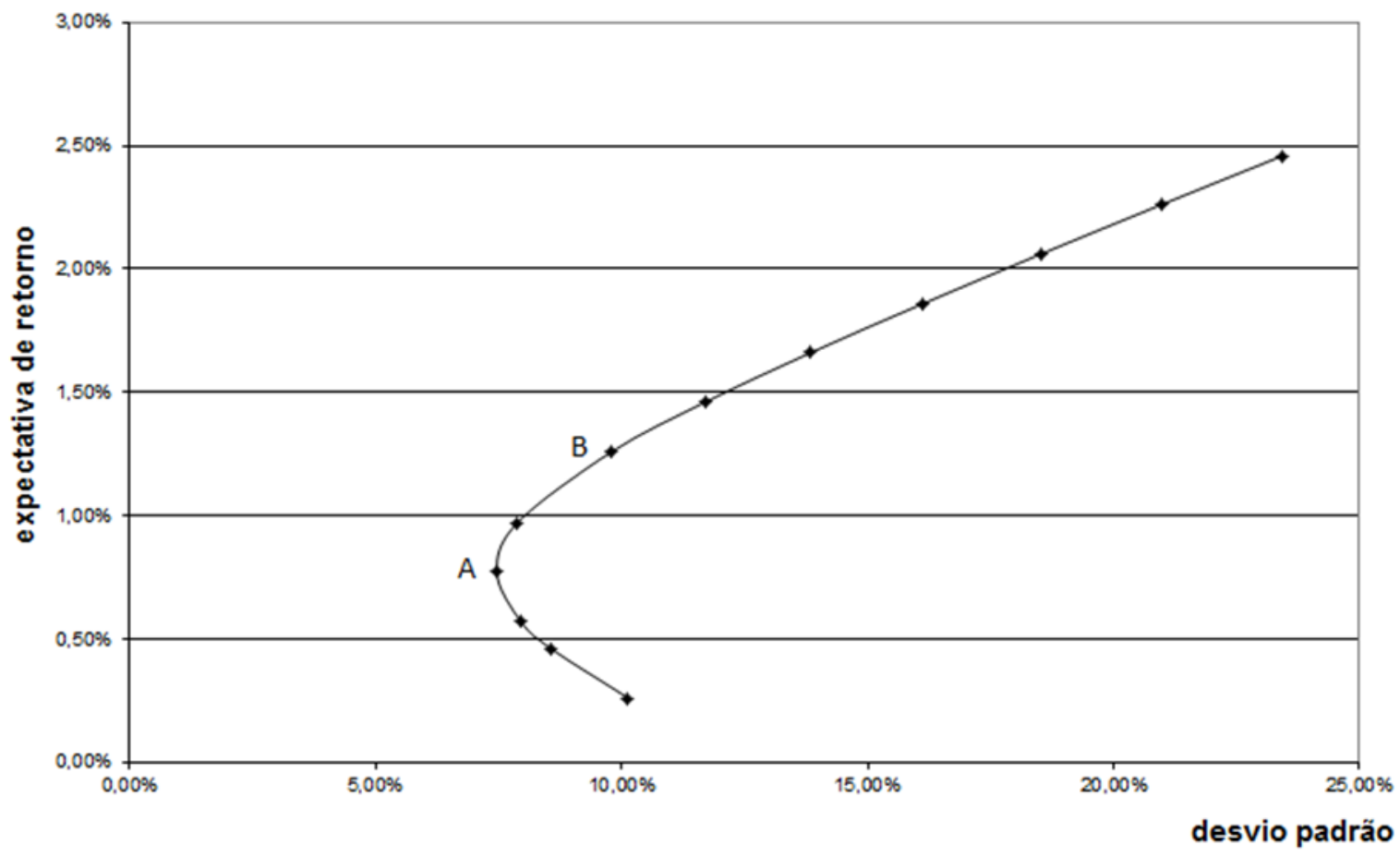

Gráfico 3 - Fronteira Eficiente

A partir do Gráfico 3, é possível verificar que a combinação que proporciona o menor risco perante todos os conjuntos é a carteira $\mathrm{A}$, que possui um risco de $7,45 \%$ para um retorno de $0,77 \%$. Vale lembrar que, para investidores avessos ao risco, esse é o melhor conjunto risco-retorno considerando uma carteira formada pelas três unidades de negócio no período analisado. As demais carteiras, mesmo que apresentando retornos maiores, oferecem riscos superiores também.

Atualmente, a empresa encontra-se em um contexto em que $60 \%$ de seus recursos estão alocados na unidade máquinas-ferramenta, enquanto que o restante está distribuído em $4 \%$ para máquinas (injetoras) para plásticos e $36 \%$ para fundidos e usinados (considerando a média do imobilizado de cada unidade no período 1T/2012 até 3T/2013). Assim, para que se tenha a carteira A, de menor risco possível, seria necessário redistribuir o investimento da empresa da seguinte maneira: 
40,6\% para máquinas-ferramenta, 5,6\% para máquinas para plásticos e 53,8\% para fundidos e usinados, o que significaria reduzir o investimento na unidade máquinas-ferramenta e aumentar os investimentos em máquinas para plásticos e, principalmente, em fundidos e usinados (que apresenta o menor risco). Dessa forma, a empresa passaria a vivenciar um cenário em que todo seu investimento estaria dividido de forma a compor uma carteira de menor risco.

Outras combinações poderiam ser formadas buscando-se aumentar o retorno (o que acarretaria também em um aumento no risco). Por exemplo, a carteira B, com retorno de $1,26 \%$, resultaria em um risco de $9,8 \%$, ou seja, comparando-se com a carteira A (que proporciona o menor risco), ao elevar o retorno em $164 \%$ (de $0,77 \%$ para $1,26 \%$ ), seu risco seria elevado em $131 \%$ (de 7,46\% para 9,8\%). Em outras palavras, nesse caso, um aumento no retorno acarreta em um aumento proporcionalmente menor no risco, mas esse aumento no risco não seria visto como algo vantajoso por um investidor avesso ao risco.

Para o exemplo citado (carteira B), as proporções de investimentos para cada unidade seriam: $69 \%$ para máquinas-ferramenta, 18\% para máquinas (injetoras) para plásticos e 13\% para fundidos e usinados. Nota-se que máquinas-ferramenta continua recebendo a maior parte dos investimentos, porém, máquinas (injetoras) para plásticos passaria a receber uma parcela bem maior de recursos quando comparada com a carteira $\mathrm{A}$, ao contrário de fundidos e usinados, que passaria a receber uma parcela pequena de investimento. Para formar a carteira B seria preciso ampliar o investimento nas unidades máquinas-ferramenta e máquinas (injetoras) para plásticos e reduzir o investimento na unidade de fundidos e usinados.

\section{Considerações finais}

A teoria do portfólio considera o efeito da diversificação do investimento ao alocar recursos em diferentes ativos. $\mathrm{O}$ seu maior desenvolvimento ocorreu na aplicação em ativos financeiros, pelo fato de ser possível obter uma série mais longa de informações para análise da relação risco-retorno e pelo fato de ser relativamente mais fácil investir ou desinvestir em ativos financeiros do que em ativos reais (é mais fácil, e com custos transacionais mais baixos, vender a ação de uma empresa do que vender a empresa propriamente dita).

Além disso, em investimentos em capital fixo e na composição de unidades, são consideradas questões estratégicas, aspectos mercadológicos e o know-how da empresa, além dos fatores financeiros. No entanto, a teoria do portfolio pode trazer informações importantes na composição de carteiras, considerando o retorno, o risco e a maneira como as unidades estão correlacionadas.

Uma maneira de analisar a relação risco-retorno é por meio do coeficiente de variação (CV). Os resultados sugerem que a unidade de máquinas (injetoras) para plásticos é aquela que agrega maior risco aos ativos da empresa, embora também aumente seu retorno. Já a unidade de fundidos e usinados oferece retorno relativamente baixo, sendo menor ainda que o risco fornecido por ela. Com isto, podese concluir que a unidade que mais proporciona benefícios para a empresa de maneira geral é a unidade máquinas-ferramenta.

É importante ressaltar que esse resultado apenas faz sentido se considerarmos investidores avessos ao risco, pois, para investidores não avessos aos riscos, certamente a unidade de máquinas (injetoras) para plásticos é a mais benéfica, já que trás o maior retorno, mesmo que isso signifique um elevado risco.

Atentando-se para as relações de risco-retorno individuais, para que a empresa apresente o menor risco por unidade de retorno, ela deveria investir apenas no setor de máquinas-ferramenta, isso considerando as unidades isoladamente.

Porém, ao considerar o princípio de diversificação de carteiras, proposto pela teoria de portfólio, que leva em conta a correlação entre os ativos, deve-se investir mais ou redistribuir os investimentos já existentes de forma a resultar em uma maior participação da unidade de fundidos e usinados na empresa, a fim de compor uma carteira de menor risco. Para essa carteira, seria necessário também ampliar o investimento na unidade máquinas para plástico (mesmo que tenha apresentado o pior $\mathrm{CV}$ ) e reduzir o investimento em máquinas-ferramenta (que apresentou o melhor $\mathrm{CV}$ ), como consequência da maneira como as unidades estão correlacionadas. 
Com este estudo de caso, pode-se concluir que é possível utilizar a teoria de portfólio para ampliar a gama de informações para auxiliar a tomada de decisão em relação a investimentos em diferentes unidades.

É importante ressaltar que a correlação entre as unidades analisadas é positiva e próxima de um, ou seja, apresentam comportamentos semelhantes quando expostas às mesmas situações. Assim, mesmo com toda a redistribuição dos investimentos para garantir a melhor alocação dos recursos, qualquer crise ou episódio que influencie intensamente as unidades, seja individualmente ou não, toda a empresa sofrerá com as consequências.

Uma particularidade encontrada neste trabalho e que merece destaque é a de que o período escolhido para a realização dos cálculos, embora possua uma quantidade de dados suficiente para representar o comportamento da empresa, não pode ser entendido como um comportamento fixo e duradouro, pois durante o período analisado o mundo enfrentou as crises americana e europeia. Com isto, os resultados financeiros e operacionais obtidos pela empresa certamente foram afetados por esses acontecimentos.

Vale salientar que este trabalho não está relacionado a nenhum tipo de análise das ações da empresa, nem há a pretensão de realizar a indicação de investimento ou desinvestimento. Este trabalho busca somente analisar a aplicação da teoria de carteiras, com uso amplamente difundido no mercado financeiro, no contexto de empresas e seus ativos reais. Buscou-se avançar no entendimento das relações entre as unidades de negócio, relação risco-retorno, diversificação do risco e quão factível é a aplicação desses modelos para a análise de ativos reais.

Uma limitação para este trabalho foi o período de análise devido à falta de disponibilidade de informações contábeis publicadas de maneira desagregada por unidade. Sugere-se que pesquisas futuras, quando então será possível a obtenção de uma série de dados mais longa, aplique novamente a teoria de carteiras, juntamente com índices que meçam a relação risco-retorno. Com uma série de dados mais longa, o efeito das crises não terá tanta influência sobre as informações contábeis.

Cabe destacar que este trabalho só foi possível de ser realizado pelo fato de a empresa ter passado a publicar parte de suas informações contábeis de maneira desagregada e de fácil acesso ao público. Esse tipo de transparência é uma prática rara e merece ser elogiada.

\section{Referências}

AKTER, S.; KOMPAS, T.; WARD, M. B. Application of portfolio theory to asset-based biosecurity decision analysis. Ecological Economics. v. 117, 2015.

ALBERTON, A. Meio Ambiente e Desempenho Econômico-Financeiro: o Impacto da ISO 14001 nas Empresas Brasileiras. 2003. 307 f. Tese (Doutorado em Engenharia de Produção) - Programa de Pós-Graduação em Engenharia de Produção (PPGEP), Universidade Federal de Santa Catarina (USFC). 2003.

ALLAN, G. et al. The regional electricity generation mix in Scotland: A portfolio selection approach incorporating marine technologies. Energy Policy. v. 39. 2011.

ANDRADE, V. R. A. Efeitos da diversificação no valor das empresas do mercado de telecomunicações: teste do modelo de Berger e Ofek. 2002. 150 p. Dissertação (Mestrado em Administração) - Departamento de Administração, Universidade de São Paulo, São Paulo, 2002.

ANDRADE, V. R. A.; FAMÁ, R. Aplicação dos conceitos de risco e retorno para avaliação das unidades estratégicas de negócio: em estudo exploratório. SEMINÁRIOS EM ADMINISTRAÇÃO, 4. 1999, São Paulo. Anais... IV SEMEAD, USP/SP, 1999

ANDRADE, V. R. A.; FAMÁ, R. Aplicação de índices financeiros na avaliação de unidades estratégicas de negócio e a decisão de investimento baseada no risco de cada unidade: um estudo exploratório. Revista de administração da USP. São Paulo, v. 36, n.2, p. 67-79, 2001. 
ASSAF NETO, A. Estrutura e análise de balanços: um enfoque econômico-financeiro. 8 ed. São Paulo: Atlas, 2006.

BAMPI, R. E.; CAMARGO, M. E.; COLOMBO, J. A. Redução de risco na formação de carteiras: um estudo da correlação das ações do Ibovespa. In: SIMPÓSIO DE ENGENHARIA DE PRODUÇÃO, 16. , 2009, Botucatu. Anais... XVI SIMPEP, 2009.

BERNSTEIN, P. L. Desafio aos deuses: a fascinante história do risco. 2 ed. São Paulo: Campus, 1997.

BODIE, Z.; KANE, A.; MARCUS, A. J.: Investimentos. 8 ed. Porto Alegre: AMGH, 2010.

BRASHEAR, J. P.; BECKER, A., GABRIEL, S. Interdependencies among E\&P projects and portfolio risk management. In: SPE ANNUAL TECHNICAL CONFERENCE AND EXHIBITION, 1999, Houston, Texas. Proceedings... Houston: Society of Petroleum Engineers, 1999.

BROWN, K.; REILLY, F. Investiment analysis and portfolio management. 10 ed. New Delhi: Cengage, 2010.

BRUNI; A. L.; FAMÁ, R. Mercados eficientes, CAPM e anomalias: uma análise das ações negociadas na Bovespa (1988 - 1996). In: SEMINÁRIOS EM ADMINISTRAÇÃO, 3. 1998, São Paulo. Anais... III SEMEAD, USP/SP, 1998.

BYERS, S. S.; GROTH, J. C.; SAKAO, T. Using portfolio theory to improve resource efficiency of invested capital. Journal of cleaner production. v. 98, 2015.

CLARK, J.; DOWNING, D. Estatística aplicada. 2 ed. São Paulo: Saraiva, 2006.

CORD, J. A method for allocating funds to investment projects when returns are subject to uncertainty. Management Science. v. 10, n. 2, 1964.

DAMODARAN, A. Finanças corporativas: teoria e prática. 2 ed. Porto Alegre: Bookman, 2004

DAMODARAN, A. A avaliação de empresas. 2 ed. São Paulo: Pearson Prentice Hall, 2007.

DELARUE, E. et al. Applying portfolio theory to the electricity sector: Energy versus power. Energy Economics. v. 33. 2011.

FAMÁ, R.; GALDÃO, A. A função financeira: uma análise esquemática de sua evolução. In: SEMINÁRIOS EM ADMINISTRAÇÃO, 1. , 1996, São Paulo. Anais... I SEMEAD, USP/SP, 1996.

FAMÁ, R.; SAITO, A. T.; SAVOIA, J. R. F. A evolução da função financeira. Revista de Gestão USP, São Paulo, v. 13, n. especial, p. 31-44, 2006.

GAO, C.; SUN, M.; SHEN, B.; RANRAN, L.; TIAN, L. Optimization of China's energy structure based on portfolio theory. Energy. v. 77, 2014.

GOMES, S. M. B. R.; MARREIROS, J. R. R. Diversificação: estratégia empresarial. Instituto Superior de Engenharia de Coimbra, 2008.

GONÇALVES, C. A. S.; MORAES, L. P.; PIMENTA, A. F. N. As distribuidoras de gás: um enfoque econômico-financeiro. In: SIMPÓSIO DE ENGENHARIA DE PRODUÇÃO, 17., 2010, Bauru. Anais... XVII SIMPEP, 2010. 
GUERRERO-LEMUS, R.; MARRERO, G.A.; PUCH. L. A. Costs for conventional and renewable fuels and electricity in the worldwide transport sector: A mean-variance portfolio approach. Energy. v. 44. 2012.

GUIMARÃES JUNIOR, F. R. F. et al. Desempenho de carteiras formadas com base em value drivers. In: ENCONTRO NACIONAL DE ENGENHARIA DE PRODUÇÃO, 31., 2011, Belo Horizonte. Anais... XXXI ENEGEP, 2011.

HOWELL III, J. I.; ANDERSON, R. N.; BENTZ, B. Managing E\&P assets from a portfolio perspective. Oil \& Gas Journal. v. 96, n. 48, 1998.

JONES, W. A. How the portfolio approach aids exploration strategic planning. In: SPE ANNUAL TECHNICAL CONFERENCE AND EXHIBITION, 1985, Las Vegas, Nevada. Proceedings... Houston, Texas: Society of Petroleum Engineers, 1985.

LEMME, C. F. Revisão dos modelos de avaliação de empresas e suas aplicações nas práticas de mercado. Revista de Administração da USP. v. 36, n. 2, 2001.

LIMA, C. M. M.; SILVA, M. D. O. P.: Indicadores de rentabilidade: uma avaliação da empresa Acumuladores Moura S/A antes e depois da certificação ISO 14001. In: SIMPÓSIO DE ENGENHARIA DE PRODUÇÃO, 16., 2009, Botucatu. Anais...XVI SIMPEP, 2009.

MARKOWITZ, H. Portfolio Selection. The Journal of Political Economy, Oxford, v.7, p. 77-91, 1952.

MARKOWITZ, H. Portfolio Selection: efficient diversification of investments. 3 ed. New Haven: Yale University Press, 1959.

MEDIMOREC, D.; TOMSIC, Z. Portfolio theory application in wind potential assessment. Renewable energy. v. 76, 2015.

NEPOMUCENO, F. F. Tomada de decisão em projetos de risco na exploração de petróleo. 1997. Tese (Doutorado em Geociências). Instituto de Geociências. Universidade Estadual de Campinas, Campinas, 1997.

ORMAN, M. M.; DUGGAN, T. E. Applying modern portfolio theory to upstream investment decision making. Journal of Petroleum Technology. v. 51, n. 3, 1999.

QUICK, A. N.; BUCK, N. A. Viability and portfolio analysis as tools for exploration strategy development. Journal of Petroleum Technology. v. 36, n. 4, 1984.

ROMI S.A. Breve histórico da Romi. 2012. Disponível em: 〈www.romi.com.br〉. Acesso em: 22 Abr. 2012.

ROQUES, F.; HIROUX, C. SAGUAN, M. Optimal wind power deployment in Europe - A portfolio approach. Energy Policy. v. 38, 2010.

ROQUES, F.A.; NEWBERY, D.M.; NUTTALL, W.J. Fuel mix diversification incentives in liberalized electricity markets: a Mean-Variance Portfolio theory. Energy Economics. v. 30. Jul. 2008.

SECURATO, J. R. O modelo de Markowitz na administração de carteiras. Revista Brasileira de Mercado de Capitais, São Paulo, v. 64, p. 17-20, 1997. 
SILVEIRA, A. M. et al. Os fundos de ações e a alocação ótima de ativos proposta por Markowitz. Revista da Adesa, Rio de Janeiro, n. 10 e 11, 2006.

SIMPLICIO' J. G.; LEMME C. F.; LEAL, R. P. C. Teoria de carteiras na seleção de projetos de investimento em petróleo. Gestão \& Produção. V. 19, n 2. São Carlos, 2012.

SMITH, C. W. The Theory of Corporate Finance: A Historical Overview. In: JENSEN, M. C.; SMITH, C. W. The modern theory of corporate finance. New York, McGraw-Hill, 1984.

WALLS, M. R. Combining decision analysis and portfolio management to improve project selection in the exploration and production firm. Journal of Petroleum Science and Engineering. v. 44, 2004. 